\title{
Prevalência de Chlamydia trachomathis em amostras endocervicais de mulheres em São Paulo e Santa Catarina pela PCR
}

\author{
Prevalence of Chlamydia trachomatis in endocervical samples by PCR in São Paulo and Santa Catarina
}

Marcos Edgar Herkenhoff'; Rodrigo Gaulke²; Luisa Lemos Vieira3;

unitermos

Chlamydia trachomatis

PCR

Endocervical

\section{resumo}

Introdução: Nenhuma outra doença sexualmente transmissível (DST) tem mostrado frequência tão elevada quanto a infecção por Chlamydia trachomatis (CT). É frequente a detecção de mulheres portadoras de danos tubários causados por esse agente, determinando infertilidade permanente e as intervenções cirúrgicas não têm demonstrado sucesso em reparar esses danos. A reação em cadeia da polimerase (PCR) se mostrou mais sensivel do que a cultura para a identificação de CT, principalmente em cervicite clamidiana nas mulheres. A PCR promove a detecção de sequências específicas de nucleotídeos para a CT. Objetivo: Analisar a prevalência de infecções causadas pela CT em mulheres nos estados de São Paulo e Santa Catarina utilizando amostras endocervicais. Materiais e métodos: Utilizaram-se para o presente trabalho amostras enviadas pelos laboratórios conveniados ao Genolab, pertencentes aos estados de São Paulo e de Santa Catarina. Foram consultados os resultados dos laudos de exames para CT oriundos do banco de dados do Genolab no ano de 2010. Para a obtenção e o isolamento do ácido desoxirribonucleico (DNA), utilizou-se a técnica de fenol-clorofórmio e para a amplificação do material genético, a técnica de PCR. Resultados: Obteve-se uma amostra de 287 indivíduos, e desse total $56,45 \%$ das mulheres eram positivas. A amostra que obteve o maior número de positivos foi o swab endocervical, com $75 \%$. Conclusão: As amostras biológicas provenientes do endocérvix apresentaram detecção eficiente da CT na população feminina. A alta prevalência salienta a importância no emprego do diagnóstico molecular, principalmente por este trabalho apontar esse aspecto.

\section{abstract}

Introduction: No other sexually transmitted disease (STD) has been as frequent as Chlamydia trachomatis (CT) infection. Tubal damage caused by this agent has been frequently detected among women. This infection causes permanent infertility. Furthermore, surgical interventions have not demonstrated success in repairing tubal damage. The polymerase chain reaction $(P C R)$ has proved to be more sensitive than culture to the identification of CT mainly in women with chlamydial cervicitis. PCR promotes the detection of specific nucleotide sequences in CT. Objective: To analyze the prevalence of infections caused by CT in women in São Paulo and Santa Catarina states by use of endocervical samples. Material and methods: In this study we used samples from laboratories in São Paulo and Santa Catarina states, which are associated with Genolab. CT examination result reports from 2010 obtained from Genolab database were analyzed. The phenol-chloroform protocol was used to obtain and isolate deoxyribonucleic acid (DNA) and the (PCR) method was used to amplify genetic material. Results: We obtained a sample of 287 individuals, of which 56.45\% were positive. Endocervical swab samples showed the highest positive results (75\%). Conclusion: Endocervical samples constituted an accurate detection of CT. The high prevalence emphasizes the importance of molecular diagnosis, which is also corroborated by this study. key words

Chlamydia trachomatis

PCR

Endocervical

\footnotetext{
1. Mestrando em Ciência Animal (área de Genética) pela Universidade do Estado de Santa Catarina (UDESC); veterinário.

2. Graduando em Biomedicina pelo Centro Universitário Leonardo da Vinci (UNIASSELVI/FAMEBLU); técnico em análises genéticas.

3. Mestranda em Ciência Animal (área de Diagnóstico Molecular) pela UDESC; veterinária; revisora.

4. Mestranda em Ciência Animal (área de Virologia e Microbiologia) pela UDESC; veterinária; revisora.

5. Mestrado em Biotecnologia pela Universidade Federal de Santa Catarina (UFSC); responsável técnica do Cenolab Análises.

6. Doutora em Patologia Clínica pela Universidade de São Paulo (USP); diretora científica do Cenolab Análises.
} 


\section{Introdução}

A Chlamydia trachomatis (CT) pode ser considerada o agente etiológico de conjuntivites e infecções respiratórias em pacientes com até um ano de vida. É também considerada uma doença sexualmente transmissível (DST) quando infecta e coloniza o trato sexual e genital. Sua real prevalência é desconhecida pelo provável fato de ser muitas vezes assintomática ${ }^{(18)}$. É uma bactéria Gram-negativa e intracelular obrigatória. É o agente etiológico mais comumente associado às DSTs nos Estados Unidos ${ }^{(11)}$.

Nenhuma outra DST tem mostrado frequência tão elevada quanto a infecção por CT. É frequente a detecção de mulheres portadoras de danos tubários, por vezes irreversíveis, causados por esse agente, determinando infertilidade permanente. A intervenção cirúrgica, como as salpingoplastias e as salpingólises não têm demonstrado sucesso em reparar os danos tubáricos causados pela doença inflamatória pélvica (DIPA) ${ }^{(8,19)}$. Além disso, a infecção causada pela CT tem sido associada a complicações relacionadas com a reprodução e a saúde na população feminina, incluindo infertilidade e gravidez ectópica ${ }^{(13)}$, sendo considerada o maior agente responsável por esse tipo de gravidez ${ }^{(28)}$. A presença da $\mathrm{CT}$ está associada às alterações citológicas da cérvix uterina ${ }^{(21)} \mathrm{e}$, segundo Mardh et al.(17), é o agente comum da salpingite aguda.

Em um estudo realizado na Polônia, a prevalência de $\mathrm{CT}$ em casos de abortos precoces foi alta. Isso implica, sobretudo, prevenção contra esse agente em mulheres que planejam engravidar e também nas que já estão grávidas ${ }^{(16)}$. A prevalência desse agente também é alta em mulheres grávidas atendidas na Unidade de Terapia para Infecções Genitais na Universidade Estadual paulista (UNESP) e tem sido associada a muitos fatores de risco. Portanto, a sua triagem é extremamente importante para reduzir complicações obstétricas e neonatais ${ }^{(23)}$. Além disso, a CT genital pode provocar dor durante a relação sexual, reduzindo a satisfação e a qualidade do sexo em mulheres jovens sexualmente ativas $^{(4)}$.

A infecção por esse agente é um cofator importante na transmissão do vírus da imunodeficiência humana (HIV), tanto no homem como na mulher ${ }^{(19)}$. Em contrapartida, muIheres recentemente infectadas com HIV-1 e HIV-2 aumentam as chances de infecção por Neisseria gonorrhoeae e $\mathrm{CT}^{(33)}$.

Um estudo realizado em Portugal demonstrou que a prevalência real de CT é desconhecida e o fato é atribuído à alta taxa de casos assintomáticos(18). Um outro estudo, realizado em Porto Rico, concluiu que existe uma falta de compreensão por parte da população quanto à infecção desse agente e isso tem mostrado uma verdadeira carência de conhecimento. Sem o entendimento necessário acerca desse agente, estudantes de medicina e médicos são incapazes de identificar a presença deste e, subsequentemente, educar seus pacientes sobre a prevenção e as complicações sérias dessa infecção. Isso tem uma implicação grave na saúde da mulher e esse conhecimento é importante para reduzir a taxa de pessoas infectadas ${ }^{(15)}$.

A infecção desse agente constitui um sério problema para a saúde pública na América do Sul(1). Um estudo mostrou que existe a circulação desse agente até mesmo em populações indígenas da Amazônia brasileira ${ }^{(9)}$. Outro trabalho indicou que a Alemanha possui uma prevalência desse agente muito semelhante a outros países ${ }^{(7)}$, ou seja, a infecção causada por CT constitui um problema de saúde pública em todo mundo.

Abuso de álcool, uso incorreto de preservativos, hábitos sexuais e falta de conscientização (incluindo a natureza dos sintomas) são identificados como promotores para o desenvolvimento da infecção por esse agente e outras DSTs ${ }^{(20)}$. Portanto, visto que é um agente com alta prevalência no mundo, faz-se necessário o emprego de metodologias de diagnóstico e monitoria adequada da $\mathrm{CT}^{(1)}$. Entre a vasta gama de metodologias, a mais utilizada é a identificação por métodos sorológicos ${ }^{(9,28)}$, no entanto, é fundamental o emprego de metodologias da Biologia Molecular na identificação, principalmente pelo material genético, do

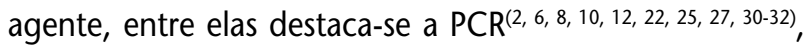
por possuir eficácia e sensibilidade de $100 \%$, enquanto o imunoensaioenzimático, por exemplo, possui sensibilidade de $58,8 \%$ e especificidade de $100 \%^{(14)}$.

O objetivo deste trabalho é estimar a prevalência da CT em mulheres no estado de São Paulo e Santa Catarina com amostras coletadas no endocérvix, oriundas de um laboratório de Análises Genéticas em Blumenau-SC, por meio da técnica de PCR.

\section{Material e métodos}

\section{Obtenção e coleta do material}

Utilizou-se para o presente trabalho amostras de swab e raspado endocervical enviadas pelos laboratórios conveniados ao Genolab, pertencentes aos estados de São Paulo e Santa Catarina. Foi recomendado que a coleta fosse 
realizada seguindo o manual de coleta Genolab 2010. Nesse manual, seguem as seguintes recomendações: amostras refrigeradas $\left(4^{\circ} \mathrm{C}\right.$ em até três dias), nenhuma orientação no preparo do paciente e o material biológico deve ser colocado em tubos contendo solução salina. A coleta do material de raspado endocervical foi feita mediante ao uso de citobush. Coletou-se e avaliou-se a idade das pacientes. Não foi possível a coleta de outros dados relevantes para a análise, como paridade, parceiros sexuais, classe social, uso de contraceptivos ou vulnerabilidade para aquisição do agente, pelo fato desses dados não constarem nos laudos por se tratar de informações sigilosas entre médico e paciente.

\section{Extração de DNA e amplificação}

Para a obtenção e o isolamento do DNA, utilizou-se a técnica de fenol-clorofórmio(24). Para a amplificação do material genético de interesse, foi aplicada a técnica de PCR.

\section{Análise dos laudos e análise estatística}

Foram consultados os resultados dos laudos de exames para a detecção do agente $\mathrm{CT}$, oriundos do banco de dados do Genolab, no período de um ano. Quantificaram-se, assim, amostras de 287 indivíduos.

\section{Resultados}

Obteve-se um total de 287 pacientes que solicitaram exame para CT enviando amostras endocervicais. Em relação à idade observada das pacientes (Figura), a média foi de 34 anos; a mediana demonstrou o mesmo valor, enquanto a idade apresentou a maior frequência (moda): 32 anos. Das 287 amostras, 56,45\% eram positivas e $43,55 \%$ negativas quanto à detecção da CT. Desse total, $13,94 \%$ foram coletadas por swab, enquanto $86,06 \%$, por raspado. Em relação às amostras coletadas por swab, 75\% apresentaram-se positivas e $25 \%$, negativas. Já as amostras coletadas com raspado, $53,44 \%$ eram positivas e $46,56 \%$, negativas (Tabela).

\section{Discussão}

A idade das pacientes variou de 17 a 58 anos. A média e mediana foram de 34 anos e a moda foi de 32 anos. Até

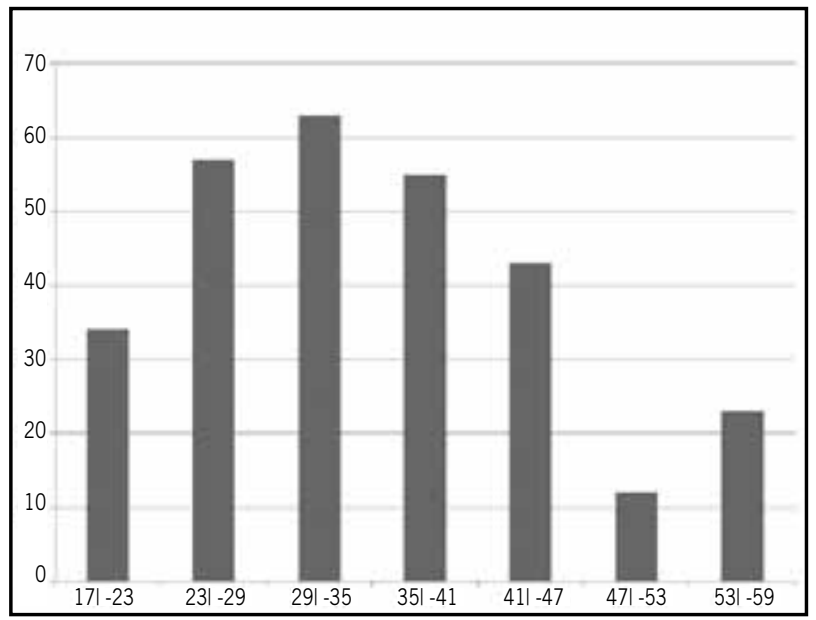

Figura - Frequência da idade das pacientes neste estudo

Frequência positiva e negativa das amostras analisadas em relação às amostras de swab, raspado e amostragem

Tabela total

\begin{tabular}{l|c|c|}
\multicolumn{1}{|c|}{ Amostras } & Positivo (\%) & Negativo (\%) \\
\hline Swab endocervical & 75 & 25 \\
\hline Raspado endocervical & 53,44 & 46,56 \\
\hline Total & 56,45 & 43,55 \\
\hline
\end{tabular}

os 46 anos, todos os intervalos de classe se mostraram relativamente altos, no entanto, após essa idade as classes mostraram intervalos baixos (Figura). Isso demonstra claramente a falta de acompanhamento por parte das mulheres com idade um pouco mais avançada.

A amostra total mostrou prevalência extremamente alta. O trabalho de Arráiz et al. ${ }^{(1)}$ apresentou prevalência de 13,7\% para pacientes sintomáticas, 7,4\% para assintomáticas e $10,4 \%$ no total, nos três casos com amostras coletadas por swab endocervical. Jenab et al. ${ }^{(10)}$, com o mesmo tipo de amostra, mostraram prevalência de $21,25 \%$. Patel et al. ${ }^{(22)}$, em um trabalho realizado na Índia coletando-se, também, amostras do endocérvix por meio de swab, mostraram prevalência de $23 \%$. Ramos et al. ${ }^{(23)}$ apresentaram prevalência de $25,7 \%$ em uma amostra de endocérvix no Hospital Universitário da Universidade Estadual Paulista (UNESP). Santos et al. ${ }^{(25)}$ mostraram prevalência de $20,7 \%$ na população de Manaus-AM também com amostras do endocérvix. Portanto, em comparação com os demais trabalhos, a prevalência de $56,45 \%$ encontrada no presente trabalho seria considerada bem alta, uma vez que no trabalho de Arráiz et al.(1) os valores encontrados apontam prevalência alta, sendo a PCR a técnica empregada em todos os trabalhos citados, bem como neste. 
A técnica de referência para o diagnóstico desse agente ainda é o cultivo, que possui especificidade de quase 100\%; no entanto, a sensibilidade não é muito boa ${ }^{(1,3,5,29,34,35)}$. Esse tipo de exame requer cultivo de linhagens celulares e estas são de alto custo e de difícil conservação, fazendo com que muitos laboratórios abandonem essa prática ${ }^{(1)}$. Os testes de amplificação, como a PCR, são mais dispendiosos do que os demais testes não culturais, mas de menos custo do que a cultura, demonstrando sensibilidade e especificidade de quase $100 \%{ }^{(26)}$. Além disso, essa técnica pode ser utilizada como método de prevenção sem que o paciente possua alguma manifestação clínica, uma vez que ela detecta o agente antes que ele se reproduza a ponto de manifestar o quadro clínico ${ }^{(1,26)}$. A eficácia da técnica da PCR justifica seu emprego no presente trabalho.

As amostras coletadas por meio de swab mostraram prevalência muito maior $(75 \%)$ do que as coletadas por meio de raspado $(53,44 \%)$. Todavia, o total de pacientes com amostras coletadas por swab é muito inferior ao total coletado com raspado, mesmo assim, isso é forte indicativo de que o swab, assim como nos trabalhos anteriores $(1,10,22,23,25)$, é mais eficiente do que o raspado na obtenção de material de melhor qualidade para o diagnóstico molecular, mesmo que possa parecer controverso.

\section{Conclusão}

Os valores apresentados neste trabalho mostram prevalência extremamente alta da CT nos dois estados, sendo a prevalência mais alta em Santa Catarina do que no estado de São Paulo. Visto que a CT afeta a qualidade da vida sexual da paciente e pode provocar problemas sérios à fertilidade, existe a necessidade de um controle epidemiológico mais eficaz nesses dois estados. Portanto, este trabalho salienta a importância de se realizar o diagnóstico laboratorial para esse agente, principalmente mediante o emprego da PCR como técnica, por esta ter mostrado sensibilidade e especificidade elevadas. $O$ trabalho salienta também a necessidade de monitoramento mais rigoroso em mulheres com idade um pouco mais avançada para a detecção desse agente.

\section{Referências}

1. ARRÁIZ, R. N.; GINESTRE, P. M.; PEROZO, M. A.; CASTELLANO, G. M.; URDANETA, B.; GARCIA, G. M. M. Diagnóstico molecular y prevalência de infecciones por Chlamydia trachomatis em pacientes sintomáticas y asintomáticas de uma población del estado de Zulia, Venezuela. Rev Chil Infect, v. 24, n. 1, p. 48-52, 2007.

2. BASS, C. A.; JUNGKIND, D. L.; SILVERMAN, N. S.; BONDI, J. M. Clinical evaluation of new polymerase chain reaction assay for detection of Chlamydia trachomatis in endocervical specimens. Journal of Clinical Microbiology, v. 31, n. 10, p. 2648-53, 1993.

3. BLACK, C. M. Current methods of laboratory diagnosis of Chlamydia trachomathis infections. Clin Microbiol Rev, v.10, p. 160-84. 1997.

4. CAI, T. et al. Genital Chamydia trachomatis infection is related to poor sexual quality of life in young sexually active women. Journal Sex Med, v. 8, n. 4, p. 1131-7, 2011.

5. CDC, Centers of Disease Control and Prevention. Sexually transmitted diseases treatment guideless. MMWR Morb Mortal Wkly Rep. 2002.

6. DEAN, D. et al. Predicting phenotype and emerging strains among Chlamydia trachomatis infections. Emerging Infectious Diseases, v. 15, n. 9, 2009.

7. DESAI, S.; MEYER, T.; THAMM, M.; HAMOUDA, O.; BREMER, V. Prevalence of Chlamydia trachomatis among young German adolescents, 2005-06. Sexual Health, v. 8, n. 1, p. 120-2, 2011.
8. FERRERO, D. V.; MEYERS, H. N.; SCHULTZ, D. E.; WILLIS S. A. Performance of the Gen-Probe AMPLIFIED Chlamydia trachomatis in detecting Chlamydia trachomatis in endocervical and urine specimens from women and urethral and urine specimens from men attending sexually transmitted disease and family planning clinics. Journal of Clinical Microbiology, v. 36, n. 11, p. 3230-3, 1998.

9. ISHAK, M. O. G.; ISHAK, R. O impacto a infecção por Chlamydia em populações indígenas da Amazônia brasileira. Cad Saúde Pública, v. 17, n. 20, p. 385-96, 2001.

10. JENAB, A.; ROGHANIAN, R.; GOLBANG, N.; GOLBANG, P.; CHAMANI-TABRIZ, L. Comparison of three methods of DNA extraction in endocervical specimens for Chlamydia trachomatis infection by spectrophotometry, agarose gel, and PCR. Arch Immunol Ther Exp, v. 58, p. 227-34, 2010.

11. KNOWLTON, A. E.; BROWN, H. M.; RICHARDS, T. S.; ANDREOLAS, L. A.; PATEL, R. K.; GRIESHAB, S. S. Chlamydia trachomatis infection causes mitotic spindle pole defects independently from its effects on centrosome amplification. Traffic, 2011.

12. LEHMUSVUORI, A.; JUNTUNEN, E.; TAPIO, A.; RANTAKOKKO-JALAVA, K.; SOUKKA, T.; LÖVGREN, T. Rapid homogeneous PCR assay for the detection of Chlamydia trachomatis in urine samples. Journal of Microbiological Methods, v. 83, p. 302-6, 2011.

13. LEÓN, S. R. et al.; NIMH COLLABORATIVE HIVISTD PREVENTION TRIAL GROUP. Chlamydia trachomatis 
infection associated risk factors in a low-income marginalized urban population in coastal Peru. Rev Panam Salud Publica, v. 26, n. 1, p. 39-45, 2009.

14. LOEFFELHOLZ, M. J. et al. Detection of Chlamydia trachomatis in endocervical specimens by polymerase chain reaction. Journal of Clinical Microbiology, v. 30, n. 11, p. 2847-51, 1992.

15. LÓPEZ-CEPERO, R.; FLARES, J. A.; ROMAGUERA, J. Knowledge of Chlamydia trachomatis assessed in a Puerto Rican medical student population. PRHSJ, v. 30, n. 1, p. 18-21, 2011.

16. MAGÓN, T.; KLUZ, S.; CHRU'SCIEL, A.; OBRZUT, B.; SKRET, A. The PCR assessed prevalence of Chlamydia trachomatis in aborted tissues. Med Wieku Rozwoj, v. 9, n. 1, p. 43-8, 2005.

17. MARDH, P. A.; RIPA, T.; SVENSSON, L.; WESTRÖM, L. Chlamydia trachomatis infection in patients with acute salpingitis. N Engl J Med, v. 296, p. 1377-9, 1977.

18. MARTINS, J.; LUÍS, C. R.; DE AGUIAR, T. C.; MARCOS, J. M. G.; BRITO, M. J. R. Infección por Chlamydia trachomatis em el primer año de vida. An Pediatr, v. 74, n. 5, p. 298-302, 2011.

19. MARQUES, C. A. S.; MENEZES, M. L. B. Infecção genital por Chlamydia trachomatis e esterilidade. Jornal Brasileiro de Doenças Sexualmente Transmissíveis, v. 17, n. 1, p. 66-70, 2005.

20. O'CONNELL, E. et al. Chlamydia trachomatis infection and sexual behavior among female student attending higher education in the Republic of Ireland. BMC Public Health, v. 9, 2009.

21. OLIVEIRA, M. L.; AMORIM, M. M. R.; SOUZA, A. S. R.; ALBUQUERQUE, L. C. B.; COSTA, A. A. R. Infecção por Chlamydia em pacientes com e sem lesões intraepitelais cervicais. Ver Assoc Med Bras, v. 54, n. 6, p. $506-12,2008$.

22. PATEL, A. L. etal. Prevalence of Chlamydia infection among women visiting a gynaecology outpatient department: evaluation of an in-house PCR assay of detection of Chlamydia trachomatis. Annals of Clinical Microbiology and Antimicrobials, v. 24, n. 9, 2010.

23. RAMOS, B. R. et al. Prevalence and risk factors of Chlamydia trachomatis cervicitis in pregnant women at the genital tract infection in obstetrics unit care at Botucatu Medical School, São Paulo State UniversityUNESP. Journal of Lower Genital Tract Disease, v. 15, n. 1, p. 20-4, 2011.

24. SAMBROOK, J.; FRITSCH, E. F.; MANIATIS, T. Molecular cloning a laboratory manual. 2. ed. Estados Unidos: Cold Spring Harbor Laboratory Press, 1989. 1886 p.

25. SANTOS, C.; TEIXEIRA, F.; VICENTE, A.; ASTOLFI-FILHO, S. Detection of Chlamydia trachomatis in endocervical smears of sexually active women in Manaus-AM, Brazil, by PCR. The Brazilian Journal of Infectious Diseases, v. 7, n. 2, p. 91-5, 2003.

26. SEADI, C. F.; ORAVEC, R.; POSER, B.; CANTARELLI, V. V.; ROSSETTI, M. L. Diagnóstico laboratorial da infecção pela Chlamydia trachomatis: vantagens e desvantagens das técnicas. J Bras Patol Med Lab, v. 38, n. 2, p. 125-33, 2001.

27. SHALEPO, K.; SAVICHEVA, E.; UNEMO, M.; DOMEIKA, M. Diagnosis of Chlamydia trachomatis in Russia - in-house
PCR assays may be effective but overall optimization and quality assurance are urgently needed. PMIS, v. 114, p. 500-7, 2006.

28. SVENSSON, L.; MARDTH, P. A.; AHLGREN, M.; NORDENSKJÖLD, F. Ectopic preganancy and antibodies to Chlamydia trachomatis. Fertil Steril, v. 44, n. 3, p. 313-7, 1985.

29. TAN, H. H.; CHAN, R. Use of polimerase chain reaction on pooled cervical swabs to detect Chlamydia trachomatis infections in female sex workers in Singapore. Singapore Med J, v. 46, p. 215-8. 2005.

30. TANG, J.; ZHOU, L.; LIU, X.; ZHANG, C.; ZHAO, V.; WANG, Y. Novel multiplex real-time PCR system using the SNP technology for the simultaneous diagnosis of Chlamydia trachomatis, Ureaplasma parvum and Ureaplasma urealyticum and genetic typing of serovars of $C$. trachomatis and $U$. parvum in NGU. Molecular and Cellular Probes, v. 25, p. 55-9, 2011.

31. VAN DER POL, B. et al. Multicenter evaluation of the AMPLICOR and automated COBAS AMPLICOS CT/NG tests for detection of Chlamydia trachomatis. Journal of Clinical Microbiology, v. 38, n. 3, p. 1105-12, 2000.

32. VAN DER POL, B. et al. Multicenter evaluation of the BDProbeTec ET system for detection of Chlamydia trachomatis and Neisseiria gonorrhoeae in urine specimens, female endocervical swabs, and male urethral swabs. Journal of Clinical Microbiology, v. 39, n. 3, p. 1008-16, 2001.

33. VENKATESH, K. K. et al. African women recently infected with HIV-1 and HSV-2 have inceased risk of acquiring Neisseria gonorrhoeae and Chlamydia trachomatis in the methods for improving reproductive health in Africa trial. Sex Transm Dis, 2011

34. WATSON, E. et al. The accuracy and efficacy of screening test for Chlamydia trachomatis: a systematic review. J Med Microbiol, v. 51, p. 1021-31. 2002.

35. YAMAKAZI, T. et al. Distribution of Chlamydia trachomatis among female prostitutes and non prostitutes in Thailand, and non prostitutes in Japan during the mid90s. Jpn J Infect Dis, v. 58, p. 215-8, 2005. 